\title{
ANTONIO MARINO*
}

\section{La Hermenéutica de Nietzsche**}

\begin{abstract}
De todo lo escrito yo amo sólo aquello que alguien escribe con su sangre. Escribe tá con sangre: y te darás cuenta de que la sangre es espíritu.

No es cosa fácil comprender la sangre ajena: yo odio a los ociosos que leen.

("Del leer y el escribir", Asi hablo Zaratustra.)
\end{abstract}

$\mathbf{P}$ ocos autores hay tan endemoniadamente herméticos como Nietzsche, pero él se distingue aun de otros porque da un giro más a sus escritos: los hace parecer llanos y de fácil acceso. Por eso él es uno de los pensadores más radicalmente malinterpretados en la historia del pensamiento. A mi juicio sólo Platón ha sido objeto de interpretaciones comparablemente erróneas. Sin embargo, la enorme complejidad de la hermenéutica de Nietzsche no puede abordarse en los 15 minutos que tengo a mi disposición. Por lo mismo, creo que mi primer deber es circunscribir el tema a explorar en esta ponencia.

Deseo limitar mi discusión de las dificultades para la interpretación del pensamiento nietzscheano a dos aspectos fundamentales: primero, el de las condiciones sine qua non de acceso a su obra, enfatizando la peculiar situación del mexicano ante ello. El segundo es el del "objeto", es decir, de las dificultades hermenéuticas consecuentes de la forma dionisíaca o antiplatónica en la cual está expresado este pensamiento.

Entender un texto siempre es una acto que se inscribe dentro de un contexto: lo dicho es significativo porque está entretejido con

*ENEP Acatlán, UNAM.

**Ponencia leída en la mesa redonda "Nietzsche, a 100 años de su locura", celebrada en el ITAM, febrero de 1989. 
un mundo. Por consiguiente, la riqueza de un texto depende de su grado de interconexión con el contexto: lo superficial es, literalmente eso, aquello que no cala, que no echa raíz en el contexto, que permanece en la periferia. Por el contrario, un texto es profundo en la medida en que abarca e interpenetra su contexto.

El contexto de todos los textos occidentales es la tradición occidental. De ahí que todo esfuerzo hermenéutico esté determinado por el conocimiento que escritor y lector tengan de ella. Nietzsche es uno de los grandes conocedores de esa tradición y todos sus textos son conversaciones y polémicas, acertijos y alusiones a la tradición occidental, en particular a sus tres raíces: Atenas, Roma y Jerusalem. Esto implica que sólo el lector formado en dicha tradición tiene las bases para realizar una interpretación competente del pensamiento nietzscheano.

Parecería ser que esta condición se puede dar por supuesta en todo lector occidental, pero si reflexionamos un instante sobre el asunto veremos que no es así. El conocimiento de la tradición en el sentido propio sólo es posible a partir del conocimiento del griego y del latín, así como de sus literaturas. La tradición sólo es accesible para el filólogo, en el sentido prístino del término, es decir, para quien tiene devoción por el logos. Pero el cutlivo del logos, a veces conocido como "humanismo", es algo casi inexistente hoy en día: prueba de ello es el abandono del estudio de las lenguas y la literatura clásicas.

El contexto de Nietzsche lo forman Homero y Fiesíodo, Esquilo y Sóflocles, Aristófanes, Sócrates y Eurípides, Virgilio y Séneca, Salustio y Juvenal, por nombrar tan sólo unos cuantos griegos y romanos. Pero el requisito para el estudioso de su pensamiento no consiste meramente en "saber quién fue fulano o mengano" sino en haber bebido profundamente en todos ellos. Es evidente que hoy son muy pocos quienes podrían ufanarse de conocer este horizonte del contexto. Gracias al positivismo de los fundadores del México moderno, no pasan de una centena los mexicanos formados en la tradición grecolatina.

Pero Nietzsche no sólo fue filólogo de profesión, lo fue en un sentido más profundo e importante: para él la palabra es la clave de todo lo humano. La palabra es la morada del hombre: lo que hace con ella se lo hace a sí mismo. En ella florece y tras ella se esconde; con ella conquista y seduce, ama y odia. Por eso sin philología no hay conocimiento profundo del hombre. La indiferencia al logos es inexorablemente misantrópica.

Un siglo después de que Nietzsche denunciaba la creciente bar- 
barie ("El desierto crece") hemos llegado muy lejos en la incuria del lenguaje. Con ello no me refiero al consabido y cotidiano abuso de la palabra por los medios masivos de comunicación, ni a las faltas de ortografia y sintaxis. Me refiero a que cada vez nos importa menos en el sentido de que nos parece normal y aceptable el desconocimiento de la genealogía de nuestro discurso. No sólo hemos relegado al basurero el latín y el griego, sino también el español. La señal más evidente de ello es la casi extinta estirpe de los poetas. ¿Quién tiene tiempo para la poesía? ¿A quién le parece de gran importancia? Hoy más bien coincidimos con Locke, quien consideraba que para un padre no había mayor tragedia que tener un hijo poeta.

Así, el obstáculo verdaderamente portentoso para el lector de Nietzsche es, más que su incultura humanista - lo que podría llamarse su "inhumanidad" - su misología: el descuido del logos, de la palabra. Sería largo dar razón del origen de esta actitud, la cual creo que está profundamente ligada con la esencia y las expectativas de la modernidad. Sin pretender ahondar en el asunto, menciono tan sólo que nosotros ciframos nuestros afanes en una sola modalidad del logos: en la matemática. La modernidad es antihumanista o misológica en cuanto se funda en el axioma de que, para usar la frase de Galileo, el libro de la naturaleza está escrito con caracteres matemáticos. Por eso mismo, el hombre, en cuanto parte de la naturaleza, sólo sería propiamente conocible en cuanto pueda ser comprendido como un sistema de ecuaciones. Como consecuencia de esta creencia llegamos a pensar que la experiencia humana es ininteligible. Paradójicamente, la hybris originaria de la modernidad es la que mata a Dios y nos vuelve nihilistas: se comienza con la creencia de que el logos en el sentido original puede ser sustituido con un lenguaje inventado por el hombre, el matemático; logrado esto, Dios sale sobrando. Pero el proyecto moderno falló hace varios siglos y por ello se recurrió a una deducción simplona: si las matemáticas son incapaces de captar por completo la verdad, peor para la verdad y para el hombre. Desde esta perspectiva, la modernidad es un empobrecimiento del logos y la Ilustración más bien la época en la que comienza la oscuridad contemporánea.

Nietzsche ataca la misología nihilista de la modernidad con su filología dionisíaca. Para comenzar a comprender el reto hermenéutico que ello significa podemos dedicar la última parte de esta sección a meditar sobre su epígrafe, el cual repito.

De todo lo escrito yo amo sólo aquello que alguien escribe con 
su sangre. Escribe tú con sangre: y te darás cuenta de que la sangre es espíritu.

No es cosa fácil el comprender la sangre ajena: yo odio a los ociosos que leen.

¿Qué significa "escribir con sangre"? Esto lo podemos comenzar a entender si lo contrastamos con otra modalidad del "escribir", la mas incorpórea y exangüe, la matemática. Escribir con sangre es expresar lo más propio, íntimo, vital de quien escribe. Es lo más lejano a la pretensión de universalidad y celestialidad de la ecuación: Mientras que el matemático desea ser comprendido por todos, "quien escribe con sangre y en forma de sentencias - dice Zaratustra - ése no quiere ser leído, sino aprendido de memoria". Escribir con sangre centra la atención en el misterio de cada cual, pone en tela de juicio que lo más profundo sea comunicable y señala como única vía de acceso la memorización. Memorizar en el sentido de incorporar al alma propia, de apropiar la sangre - quizás valgà decir, en el sentido de "transfusión".

Entre esta manera de escribir y nuestra manera de leer hoy en día hay espacios infinitos. Mientras que para Nietzsche escribir es su acto más grande de filantropía, para nosotros es una "técnica de comunicaciónn". Mientras que para él escribir es tan profundamente cuestionable como lo fue para Sócrates, para nosotros es algo que todo niño debe aprender por ley. La distancia que nos separa de Nietzsche se puede evidenciar por la oposición entre nuestras ilusiones de educación pública y la sentencia con la cual él la rechaza:

El que a todo el mundo le sea lícito aprender a leer corrompe a la larga no sólo el escribir, sino también el pensar.

Un siglo después, cuando la educación pública se ha generalizado a todos los Estados ilustrados del mundo, es difícil negarle la razón a Nietzsche. Ahora todo el mundo reconoce el síntoma, no hay país en el cual no se hable de la "crisis de la educación", si bien casi nadie piensa en la causa. Aunque reconocemos que la educación deja mucho que desear, insistimos en la creencia positivista de que mejorando los métodos pedagógicos todo el mundo aprenderá a leer y a escribir.

Por supuesto, la comprensión actual de la crisis no es la de Nietzsche: no queremos que todos aprendan a leer y escribir con sangre, nos conformamos con que puedan llenar una solicitud de 
empleo sin equivocarse.

Para concluir este apartado dirijo ahora la atención a la pregunta obligada: si Nietzsche odia a los ociosos que leen -que es la mayoria - ¿por qué escribió? Se puede responder desde dos puntos de vista, uno, explicado en el prólogo de Zaratustra, del cual me ocuparé de inmediato: el otro, se vuelve visible mediante la hermenéutica de la forma de sus escritos, y constituye el segundo apartado de esta ponencia.

En el prólogo, Nietzsche relata que cuando Zaratustra tenía treinta años y tras haber gozado de su espíritu y su soledad durante diez años, sintió deseos de regresar al hombre. Su razón es, en sus palabras, la siguiente:

iMira! Yo estoy hastiado de mi sabiduría como la abeja que ha recogido demasiada miel, yo tengo necesidad de manos que se extiendan.

Me gustaría regalar y repartir hasta que los sabios entre los hombres hayan vuelto a regocijarse con su locura, y los pobres, con su riqueza.

Con esta necesidad comienza el ocaso de Zaratustra.

Nietzsche escribe por la misma causa que Zaratustra baja al mundo: porque esta demasiado lleno de amor por el hombre. Pero esto es un defecto que debe ser erradicado, es un error de quien escribe por ello. A lo largo del primer libro de $A s i$ habló Zaratustra se evidencia porqué la compasión, querer "salvar" al hombre, es el vicio que Zaratustra no ha conquistado y que sólo conquistará en la última parte de la obra. Sin pretender más que esbozar la respuesta, me limito a decir que el afán de Zaratustra por regalarle su sabiduría al hombre tiene un resultado inmediato: se le confunde con un anunciador de circo. Esta suerte la comparte Nietzsche. Sin embargo, en cuanto la filantropía es vicio, Zaratustra y Nietzsche tienen que superarla. Esta conquista está exhibida en el ocaso y la aurora de Zaratustra y en la forma dionisíaca del libro.

La conciencia de la insuficiencia del deseo de regalar, es decir, de escribir con sangre, es el tema del último discurso de Zaratustra ante sus discípulos, en el primer libro. Tras haberlos entusiasmado y encomiado para que sigan lo que él ha predicado guarda un largo silencio y luego les dice:

En verdad, este es mi consejo: iAlejaos de mí y guardaos de Zaratustra! Y aún mejor: iAvergonzaos de él! Tal vez os ha 
engañado...

No os habíais buscado aún a vosotros: entonces me encontrásteis. Así hacen todos los creyentes: por eso vale tan poco toda la fe.

Ahora os ordeno que me perdáis a mí y que os encontréis vosotros; y sólo cuando todos hayáis renegado de mí, volveré entre vosotros.

El rechazo al lector ocioso, al discípulo que no ha renacido sino tan sólo ha escuchado, es claro. Zaratustra advierte que quien lo ha entendido así todavía no comienza a pensar. Nietzsche tampoco busca discípulos en ese sentido, pues su deseo de escribir no se basa en la necesidad de escribir -como ocurre usualmente, pues el escritor siempre busca reconocimiento- sino en la de regalar. La alusión e inversión del sentido del Evangelio de Mateo, donde Jesús dice: "A todo el que me negase delante de los hombres yo le negaré también delante de mi padre", también nos indica otro sentido en el cual Zaratustra no busca discipulos ni Nietzsche creyentes: "entender" a uno o a otro requiere mucho más que escuchar lo que dicen y aceptarlo. Sin la autognosis previa, sin primero buscarnos a nosotros mismos, permanecemos excluidos del sentido profundo de la obra de Nietzsche. En suma, Nietzsche solo escribe para filósofos.

\section{II}

¿Pero entonces qué ocurre con el lector "común y corriente", el no filóso fo? Con esta pregunta entramos al problema de la forma de la obra de Nietzsche, la cual he descrito de dos maneras: como antiplatónica y como dionisíaca. Si bien ambos calificativos se refieren al mismo asunto, los he seleccionado para distinguir dos aspectos a mi juicio centrales para la hermenéutica del pensamiento nietzscheano.

Cuando hablo del antiplatonismo de la forma de la obra de Nietzsche, me refiero a la diferencia de ésta con la forma del diálogo platónico, más que a la oposición nietzscheana a la filosofía platónica. Por supuesto, la oposición de la forma es una consecuencia inevitable de la oposición de ambas doctrinas. Sin embargo, podría haberse dado oposición de tesis sin que se buscara también la oposición de formas, tal como ocurrió múltiples veces en el pasado con quienes no concuerdan con Platón. Para hacer más inteligible esta cuestión describiré de manera sucinta a qué me refiero con la forma platónica y luego la contrastaré con la 
nietzscheana.

El primer libro de la Repríblica de Platón contiene una discusión sobre la naturaleza de la justicia. En ella se enfrentan Sócrates y Trasímaco: el primero defiende la tesis de que es preferible ser justo que ser injusto, mientras que el segundo afirma que sólo los inocentes creen eso. La enseñanza de Trasímaco, como es sabido, es una apología del poder y del poderoso que ha sido aceptada por la mayoría de quienes han reflexionado sobre la política. Traducida a términos nietzscheanos, la tesis trasimaquea es muy semejante a la idea de voluntad de poder. En el fondo lo que él enseña es que toda comunidad nace de la guerra y que las leyes tan sólo son instumentos del vencedor para someter al vencido. Dado que normalmente se entiende por "justicia" obedecer la ley y esto sólo lo hacen quienes no tienen la fuerza u hombría para ser una ley para sí mismos, Trasímaco está difundiendo una doctrina políticamente peligrosa.

Ahora bien, la forma en la cual Platón presenta la confrontación entre Sócrates y Trasímaco en el primer libro crea la ilusión de que Sócrates triunfó rotundamente sobre él. Trasímaco es presentado como un animal feroz que se lanza sobre Sócrates al inicio del argumento pero que finalmente es domado por éste. El lector superficial termina la lectura de este libro convencido de que es mejor ser justo que ser injusto. Esto es obra de la forma dramática del diálogo y no de la argumentación, pues quien la sigue con cuidado se percata de que Trasímaco se muestra amistoso con Sócrates al final de la discusión porque su tesis no ha sido propiamente refutada y Sócrates mismo lo reconoce.

Al percatarnos del efecto de la forma del diálogo platónico nos damos cuenta de que busca operar en el lector el mismo apaciguamiento que Sócrates logra con Trasímaco. Su intención es que el lector superficial no acceda a la verdadera discusión, pero que, no obstante, lo haga un hombre más virtuoso, o al menos que no lo empeore. Todos los diálogos platónicos tienen esa peculiaridad pedagógica: No causan daño al que no los entiende.

La situación con la forma de la obra nietzscheana es la opuesta. Nuevamente podemos recurrir a Así habló Zaratustra para ejemplificar el antiplatonismo. En el discurso sobre la virtud empequeñecedora, Zaratustra acaba de regresar al mundo de los hombres y relata que:

Hace poco una mujer atrajo a sí violentamente a su hijo, que quería venir a mí: íLlevaos los niños!, gritó; esos ojos chamuscan las almas infantiles. 
Nietzsche está consciente de que puede ser malinterpretado y que los malentendidos pueden ser peligrosos. De hecho, en su correspondencia llega a jactarse de que cuanto fanático hay en Europa cree encontrar en su obra una apología de su causa. Pero él escribe más bien como incendiario, con el propósito de dar fin al platonismo que ha dominado la tradición occidental por milenios. Nietzsche es propositivamente peligroso, seductor, sacrílego y ateo en la forma. Porqué asume esa forma y si está justificado en hacerlo, sería el siguiente tema a indagar, pero no en esta ocasión.

Para concluir abordaré brevemente el aspecto dionisíaco de la forma de su obra. El primer sentido de este término puede explorarse reflexionando sobre las múltiples contradicciones que se pueden encontrar en sus libros. No se trata de que él "desprecie" la lógica, sino que su pensamiento se mueve en un elemento donde la contradicción misma es significativa. En consencuencia, nunca podemos afirmar que Nietzsche "pensaba" esto o aquello y sustentarlo en la mera referencia textual. Sus escritos son más parecidos a una composición musical que a un texto de prosa, en cuanto que cada elemento forma parte de un todo y sólo adquiere su sentido pleno cuando es aprehendido en su conexión orgánica. Pero la percepción de la forma en la cual están inscritas las partes requiere oído, como él no se cansa de advertirnos. "Oir" la forma, como en el caso de la música, es algo que depende de la sensibilidad y no de la razón y la lógica. Producir una forma bella es el resultado de la inspiración; captarla también.

En Ecce homo, a propósito de la composición de Zaratustra, Nietzsche dice:

¿Tiene alguien, a finales del siglo XIX, un concepto claro de lo que los poetas de épocas poderosas denominaron inspiración? En caso contrario voy a describirlo. Si se conserva un mínimo residuo de superstición, resultaría difícil rechazar de hecho la idea de ser mera encarnación, mero instrumento sonoro, mero medium de fuerzas poderosísimas. El concepto de revelación, en el sentido de que de repente, con indecible seguridad y finura se deja ver, se deja oir algo, algo que le conmueve y transtorna a uno en lo más hondo, describe sencillamente la realidad de los hechos. Se oye, no se busca; se toma, no se pregunta quién es el que da; como un rayo refulge un pensamiento, con necesidad, sin vacilación en la forma. Yo no he tenido jamás que elegir... la involuntariedad de la imagen, 
del símbolo, es lo más digno de atención; no se tiene ya concepto alguno; lo que es imagen, lo que es símbolo, todo se ofrece como la expresión más exacta, más sencilla.

Interpretar los escritos de Nietzsche, por tanto, es una tarea colosalmente difícil. Como hemos visto, no sólo se requiere contar con un conocimiento de los griegos y los latinos: es menester haber escuchado a Calíope, Euterpe, Terpsicore, Erato, Talia y Melpómene. Por eso su obra hoy en día es "para todos y para nadie". 